\title{
EDITORIAL
}

\section{Salud de adolescentes}

L a investigación hacia la salud pública, y los beneficios potenciales derivados de la misma para orientar las políticas y programas sobre el tema, encuentran un buen ejemplo en el caso de la desarrollada sobre adolescentes que publica el presente número de Salud Pública de México. La descripción de la demanda por servicios médicos nos traza un panorama sobre los problemas que más frecuentemente enfrenta este grupo poblacional: eventos relacionados con el inicio de la actividad sexual, ya sea con miras reproductivas o no, tales como salud sexual, el VIH/SIDA o embarazo no deseado, accidentes, traumatismos y envenenamientos, cáncer, problemas relacionados con la nutrición, trastornos mentales y emocionales, tabaquismo, alcoholismo y drogadicción. Por otro lado, los diversos temas que aborda la salud de adolescentes nos dejan ver el enorme potencial que guarda la adolescencia, su gran optimismo y creatividad, su necesidad de integrarse a la sociedad productiva, a la fuerza de trabajo, su búsqueda propositiva y retadora de nuevos esquemas que ayuden a cambiar a la sociedad, así como la promesa de éxito en la vida ... o de fracaso, si no se ponen en marcha las estrategias adecuadas para atender sus necesidades. Y es por esto que la investigación tiene un papel predominante que jugar en el diseño de las políticas de salud dirigidas a esta población.

En particular, en el Instituto Mexicano del Seguro Social, institución que ofrece tanto atención médica como prestaciones económicas y sociales a más de la mitad de los habitantes del país, existe la política de utilizar a la investigación como una herramienta para ayudar en la toma de decisiones que pueden reorientar las políticas de atención a grupos vulnerables. Con esto se busca contribuir a mejorar la calidad de la atención a la población. Bajo esta premisa, esta institución ve con gran atención el presente volumen, en el cual se ha logrado no sólo la amplia recopilación de la experiencia de varios grupos de investigación alrededor del tema que nos ocupa, el cual se aborda con múltiples facetas interdisciplinarias, sino que también se ha logrado conjuntar una extensa serie de referencias bibliográficas sobre el tema, que resultarán de mucho valor para el público interesado.

La política que impulsa la institución, orientada a la atención integral a la salud, con particular énfasis en el enfoque preventivo, resulta relevante ante el planteamiento propuesto por la Organización Panamericana de la Salud, en el que se destaca el papel de la promoción de la salud de adolescentes en el contexto del desarrollo de la familia y de la comunidad. Estos son los elementos sobre los que se basa el avance en el desarrollo social, político y económico de un país. Y es, ciertamente, el rumbo en el que México desea avanzar.

La comprensión de la influencia que tiene la perspectiva de género en el desarrollo de cada adolescente resulta fundamental para poder adelantar el tipo de estrategias preventivas con sensibilidad cultural, que se requieren para impactar en el cambio de conductas. Esta perspectiva de género tiene matices muy particulares en cada sexo, representados en el varón por la violencia, la afirmación de la imagen de uno mismo ante los demás, y la necesidad de tomar un papel de dominación. En la mujer, durante esta etapa se afirma la imagen femenina, la cual puede tomar diferentes matices, dependiendo de su personalidad. Sin embargo, un aspecto consistentemente presente en esta edad es el de la imagen corporal, que puede llevar a un celo excesivo en el cuidado de la figura, con la consecuente limitación en la ingesta que lleve a la anorexia.

En forma similar, se requiere una mayor comprensión sobre sus motivaciones para incurrir en conductas de riesgo, que les llevan a problemas de morbilidad como los derivados del consumo de tabaco, alcohol o drogas, o a mortalidad, ocasionada por los accidentes, traumatismos y envenenamientos. La sensación de "invulnerabilidad" que ha sido tantas veces descrita para 
la adolescencia, la necesidad de una libertad que le permita explorar el alcance de sus capaidades, la necesidad de explorar nuevas fronteras en los límites que la sociedad adulta ha impuesto sobre el ámbito de acción de esta población, en presencia de ambientes que pueden resultar permisivos al contar con pocos referentes morales, la puede llevar a incurrir en conductas que en otras épocas de su vida muy probablemente evitaría. Y en este sentido, la información derivada de la investigación social sobre estas conductas de riesgo puede aportar datos de mucho valor para las autoridades encargadas del diseño de programas de orientación e intervención.

En suma, la información contenida en este número de Salud Pública de México resulta de inestimable valor no sólo para las instituciones encargadas de ofrecer servicios de atención a la salud, ya sea terapéuticos, de rehabilitación o preventivos, a este importante seg- mento de la población que está representado por la adolescencia, sino también para el público lector en general, que seguramente sabrá apreciar la magnífica colección de experiencia y de talento de los autores sobre un tema de indudable actualidad, y que sabrá escuchar el llamado de atención para invertir en el futuro, para cuidar y orientar a los próximos líderes de nuestro país, para trazar las políticas de salud que amplíen el espectro de la atención médica y lo dirijan más hacia la atención preventiva. Celebramos, pues, el gran acierto de Salud Pública de México para lograr reunir, en un solo volumen, este cúmulo de resultados de la investigación interdisciplinaria proveniente de diferentes instituciones, tanto públicas como privadas, que contribuirá con su información a lograr una mejor atención a la salud de este importante grupo humano.

Dr. Homero Martínez Salgado.*

* Coordinación de Investigación en Salud, Instituto Mexicano del Seguro Social. 